\title{
MAMÃO: ASPECTOS ECONÔMICOS, BIOLÓGICOS E POTENCIALIDADES NO PROCESSAMENTO PARA OBTENÇÃO DO NÉCTAR
}

\author{
Héberly Fernandes Braga ${ }^{1}$
}

${ }^{1}$ Professor Mestre do Instituto Federal de Educação, Ciência e Tecnologia do Triângulo Mineiro (IFTM), Campus Uberlândia Centro, Uberlândia-MG, Brasil.

E-mail: heberly@iftm.edu.br

Recebido em: 15/02/2020 - Aprovado em: 15/03/2020 - Publicado em: 30/03/2020 DOI: 10.18677/EnciBio_2020A12

O mercado de frutas tem crescido e especialmente o do mamão. O Brasil é segundo maior produtor mundial do fruto, entretanto ainda carece de melhorias que visem reduzir as perdas pós-colheita. O objetivo da presente revisão é disponibilizar informações técnicas acerca das características biológicas e nutricionais do mamão, bem como suas potencialidades econômicas e tecnológicas com foco no processamento e obtenção do néctar. Foram empregadas distintas referências atualizadas e informações associadas à legislação, que tivessem como norte o emprego do mamão para obtenção do néctar, visando reduzir, em especial, as perdas pós-colheita. A deficiência no manuseio, armazenagem e distribuição associados às características intrínsecas do fruto são os principais fatores que norteiam o aumento da perecibilidade. A adoção de tecnologias de processamento, como a elaboração do néctar, é uma alternativa potencial à redução das perdas, pois além de ser um processo de fácil execução e pouco oneroso, quando comparado às outras formas de conservação, permite a oferta de produto de qualidade à população ao longo de todo o ano.

PALAVRAS-CHAVE: agroindústria de processamento, bebidas não alcóolicas, mamão.

\section{PAPAYA: ECONOMIC, BIOLOGICAL AND POTENTIAL ASPECTS IN PROCESSING FOR OBTAINING NECTAR}

\begin{abstract}
The fruit market has grown and especially that of papaya. Brazil is the world's second largest producer of the fruit, but still lacks improvements to reduce postharvest losses. The aim of this review is to provide technical information about the biological and nutritional characteristics of papaya, as well as its economic and technological potential focusing on processing and obtaining nectar. Different up-to-date references and information associated with the legislation were used to guide papaya to obtain nectar to reduce postharvest losses. The deficiency in handling, storage and distribution associated with the intrinsic characteristics of the fruit are the main factors that guide the increase of perishability. The adoption of processing technologies, such as the preparation of nectar, is a potential alternative to reducing losses, because besides being an easy and inexpensive process when compared to other forms of conservation, it allows the supply of quality products. to the population throughout the year.
\end{abstract}

KEYWORDS: agro-processing industr, non-alcoholic beverages, papaya 


\section{INTRODUÇÃO}

Visando atingir o sucesso no atual ambiente competitivo do mercado alimentício, as indústrias e órgãos de pesquisa em alimentos têm investido no desenvolvimento de novos produtos, o qual está em estreita relação com as necessidades e exigências dos consumidores (COLTRE; MARTINS, 2018).

Nos últimos anos, o consumidor vem se preocupando não somente com a qualidade físico-química e higiênico-sanitária, mas principalmente com os atributos sensoriais e a qualidade nutritiva dos produtos ofertados no mercado. A seletividade e exigência, além da maior consciência da relação entre saúde e alimentação, vêm modificando os hábitos da população (DE MARCHI et al., 2016), que por sua vez afeta diretamente o setor agro alimentício e industrial.

O aumento da produção de frutas nos últimos anos, estimulado por variados fatores (ABRAFRUTAS, 2018), tem permitido o fornecimento desses alimentos à população, que muitas vezes não consegue absorver integralmente os produtos na forma in natura, os quais devem, assim, ser processados para que se reduzam perdas. Tal característica propicia a expansão da agroindústria frutícola, particularmente de sucos e derivados, a qual tem uma expressiva importância econômica no país (RITSCHEL et al., 2018).

O Brasil é considerado o terceiro maior produtor mundial de frutas (SEBRAE SIM, 2016) e dentre estas, o mamão (Carica papaya Linnaeus) vem ocupando lugar de destaque, não só em produção, como em consumo. Projeções feitas pelo Serviço Brasileiro de Apoio às Micro e Pequenas Empresas (SEBRAE) estimaram um crescimento na produção nacional de $7,13 \%$ no ano de 2018 , quando comparado ao ano de 2015 , acima de outras frutas como uva $(6,82 \%)$, banana $(2,5 \%)$, manga ($2,68 \%$ ) e laranja (- 1,40\%). Segundo dados da Fao (2016), o Brasil é o segundo país que mais produz mamão, totalizando aproximadamente 1,5 milhões de toneladas ao ano, o que corresponde a $12,5 \%$ da produção mundial.

Diante de tais perspectivas, o objetivo do presente trabalho é disponibilizar informações técnicas acerca das características biológicas e nutricionais do fruto do mamão, bem como suas potencialidades econômicas e tecnológicas enfocando o processamento e obtenção do néctar, haja visto ser esse um produto processado que apresenta baixo custo e fácil elaboração quando comparado à outras formas de processamento e conservação do fruto.

\section{MERCADO MUNDIAL DE FRUTAS E DO MAMÃO}

A fruticultura, de uma maneira geral, vem alcançando grande destaque no mundo e particularmente no Brasil, não só pela importante alternativa de diversificação e aumento de renda para a pequena propriedade, como também pela geração de empregos por se tratar de uma atividade altamente agregadora de mãode-obra e indutora da instalação de polos agroindustriais (JACOBSEN et al., 2018).

Pesquisa mostra que este setor da agricultura é responsável por mais de 865,5 milhões de toneladas produzidas mundialmente (FAO, 2018), sendo o Brasil o terceiro maior produtor de frutas, com mais de 39,8 milhões de toneladas produzidas em 2,2 milhões de hectares (FAO, 2018), ficando atrás somente da China e Índia. Apesar da alta produção e do aumento do consumo quando comparado aos anos anteriores, ainda é baixa a ingestão desses alimentos em relação aos países desenvolvidos. Segundo dados da Organização Mundial de Saúde (OMS), cada indivíduo deve consumir no mínimo $400 \mathrm{~g}$ de frutas e verduras por dia, o que equivale a aproximadamente cinco porções, entretanto estudo realizado em 2017 com adultos maiores de 18 anos em capitais brasileiras, verificou-se que somente 
$23,7 \%$ dos entrevistados consomem cinco ou mais porções de vegetais diariamente (VIGITEL BRASIL, 2018).

A grande extensão territorial com as mais diferentes condições climáticas permite que o país produza uma alta variedade de frutas ao longo do ano. Além disso, tem-se observado ascensão do mercado de frutas brasileiras a nível internacional, apesar de alguns gargalos restritivos (ABF, 2018).

Estatísticas setoriais mostram crescimento de 16,41\% (em US\$D) e 11,86\% (em toneladas) de frutas nacionais destinadas à exportação (ABRAFRUTAS, 2018). Apesar desse ligeiro crescimento, nota-se que parte da produção é demandada internamente, sendo consumida in natura e/ou processada em indústrias, especialmente porque faltam ainda muitos investimentos para poder se modernizar estradas, portos e aeroportos, facilitando a logística e rapidez na entrega aos mercados consumidores (ABF, 2018). Tais características, aliadas a burocratização no sistema de exportações, mantêm o Brasil no $23^{\circ}$ lugar dos exportadores globais, apesar de produzir o terceiro maior volume de frutas do mundo.

Para a Associação Brasileira dos Produtores e Exportadores de Frutas e Derivados (ABRAFRUTAS, 2018), o crescimento nas exportações pode aumentar especialmente se o governo investir em processos de abertura de novos mercados, como os asiáticos, que representarão entre 25 a 30 anos mais de $50 \%$ da população mundial.

A produção de mamão vem se destacando entre as diferentes frutas tropicais. Segundo a Fao (2018), em 2017 representou 1,5\% da produção mundial de frutas, perfazendo um total aproximado de 13 milhões de toneladas, dos quais 15,4\% foram produzidos na América Latina e Caribe. Os principais produtores são Índia, Brasil, México, Nigéria e Indonésia. Dentre os estados brasileiros que se destacam na produção do fruto, pode-se citar: Bahia, Espírito Santo, Ceará, Rio Grande do Norte, Minas Gerais e Paraíba (EMBRAPA, 2017).

Apesar de ser considerado o segundo maior produtor de mamão, em nível nacional o Brasil vem apresentando nos últimos anos redução nas áreas colhidas, consequente do baixo e irregular regime de chuvas e de problemas sanitários (ABRAFRUTAS, 2018), que tem afetado as regiões Sudeste e Nordeste, que representam em média 95,9\% da produção nacional (EMBRAPA, 2017). Para se ter uma ideia da redução da área colhida, segundo o IBGE (2010), em 2008 foram produzidos 1,9 milhões de toneladas do fruto no país, e já em 2017 (FAO, 2018) somente 1,0 milhão de toneladas, para uma mesma área estimada de aproximadamente 36,5 mil hectares.

Segundo Silva Júnior et al. (2017), as regiões semiáridas do território brasileiro são as que tem apresentado o mais baixo desenvolvimento inicial da cultura do mamoeiro, devido não somente à baixa pluviosidade, como também a alta insolação, e a má qualidade da água de irrigação, que muitas vezes apresenta excesso de sais. $O$ alto percentual de sais dissolvidos na solução do solo, diminui seu potencial osmótico e hídrico, reduzindo a disponibilidade de água e nutrientes às plantas, que por sua vez afetam o crescimento e produção da biomassa vegetal (DINIZ et al., 2018).

A exportação do fruto in natura ainda é considerada baixa quando comparada a outros frutos, devido principalmente aos problemas e deficiências na armazenagem e transporte. Apesar do ligeiro incremento no volume das exportações de $1 \%$ em 2019, quando comparado ao ano anterior, observa-se ainda que em 2019 a quantidade exportada foi considerada a maior (43,3 milhões de quilos), num período de cinco anos (ABRAFRUTAS, 2020). Dentre os principais 
importadores destacam-se os países da União Europeia (Portugal, Holanda, Espanha, Reino Unido, França, Itália, Alemanha e Suíça) (ABRAFRUTAS, 2018).

\section{ORIGEM, ASPECTOS BOTÂNICOS, NUTRICIONAIS E FISIOLÓGICOS DO MAMÃO}

O mamoeiro é originário do continente americano, sendo descoberto pelos espanhóis no Panamá. Atualmente encontra-se distribuído entre $32^{\circ}$ de latitude norte e sul, sendo amplamente cultivado na Índia, Sri Lanka, Arquipélago Malaio, em diferentes países da América Central, do Sul e Austrália (SALOMÃO et al., 2007).

De acordo com Serrano e Cattaneo (2010), sua possível introdução no Brasil data de 1587, sendo hoje cultivado em quase toda a totalidade do território. Segundo os mesmos autores, a cultura desenvolve-se, satisfatoriamente, em locais com temperatura média anual de $25^{\circ} \mathrm{C}$, com limites entre $21^{\circ} \mathrm{C}$ e $33^{\circ} \mathrm{C}$, e precipitação pluviométrica de $1.500 \mathrm{~mm}$ anuais bem distribuída. O fruto é produzido no país durante quase todos os meses do ano, sendo o período entre junho a agosto o de menor safra, condicionado pelas estações mais frias do ano.

A planta do mamoeiro apresenta um caule herbáceo que pode atingir de 6 a 9 $\mathrm{m}$ de comprimento, semi-lenhoso, oco e com 10 a $30 \mathrm{~cm}$ de diâmetro, geralmente não ramificado, terminando em um aglomerado de folhas digitolobadas grandes $\mathrm{e}$ glabras, com nervuras verde-amareladas, sendo sustentadas por pecíolos de 25 a $100 \mathrm{~cm}$ de comprimento, dispostos de forma espiralada ao redor do caule. As flores são pequenas, afuniladas, de coloração branca à creme, ligeiramente perfumadas, podendo ser encontradas solitárias ou formando inflorescências estaminadas, pistiladas ou hermafroditas. As superfícies dos estigmas são verdes e os estames amarelados (Figura 1) (COTRUT et al., 2017).

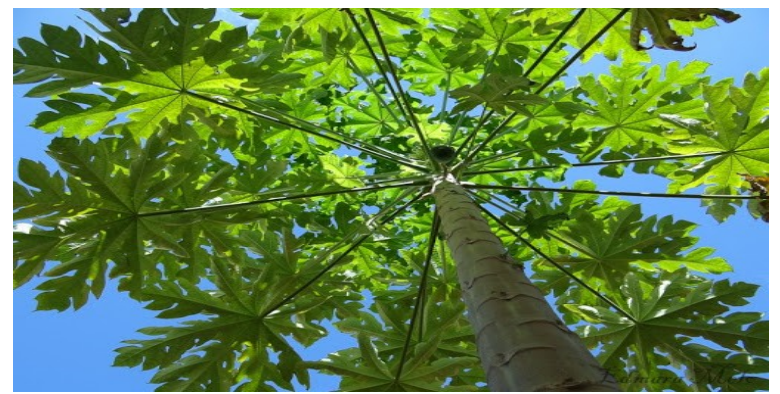

A

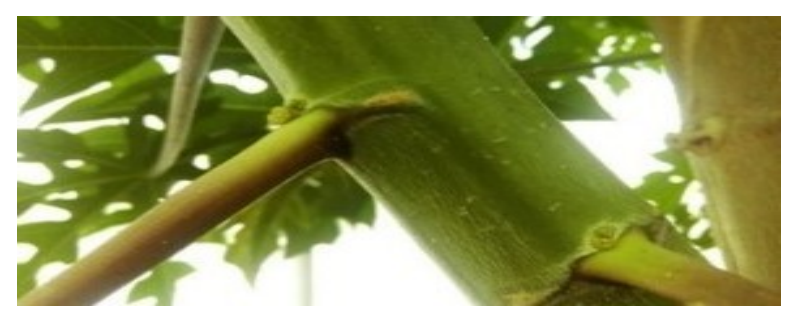

C

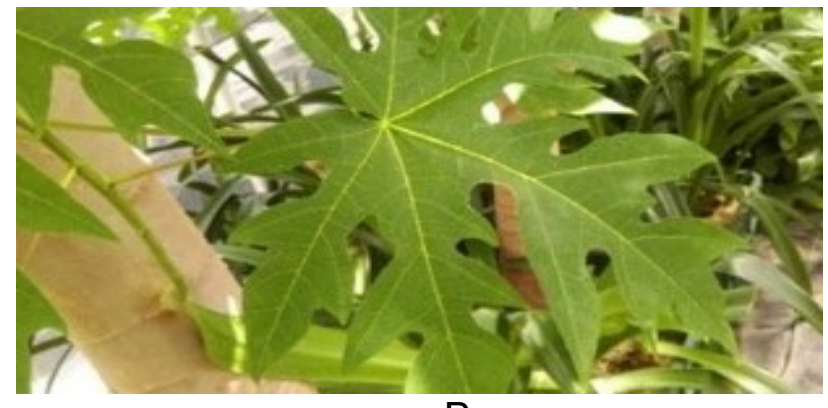

B

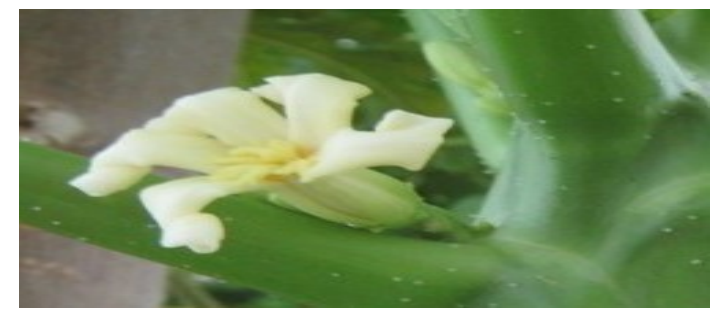

D

FIGURA 1 - Planta do mamoeiro e suas estruturas. Caule herbáceo com aglomerado de folhas no ápice (A); folha digitolobada com nervuras verdeamareladas (B); disposição espiral dos pecíolos (C); flor na axila do pecíolo (D). Fonte: Cotrut et al. (2017) e Google $\left(2020^{\mathrm{a}}\right)$ 
O mamoeiro é uma angiosperma pertence à classe Dicotyledoneae, subclasse Archichlamydeae, ordem Violales, família Caricaceae, gênero Carica, cujas principais variedades comerciais pertencem à espécie C. papaya L. (MARIN, 2004). É uma planta diploide ( $2 n=18$ cromossomos) (MING et al., 2008), perene, podendo ser dioicas ou monoicas, de crescimento rápido, com metabolismo $\mathrm{C} 3$ (CAMPOSTRINI; GLENN, 2007), que produz frutos do tipo baga, com inúmeras sementes pretas envolvidas por arilo transparente, cujo mesocarpo carnoso de coloração amarela a avermelhada é altamente apreciado in natura (Figura 2) (SALOMÃO et al., 2007), podendo ainda ser usado na elaboração de diferentes produtos e subprodutos através da industrialização.

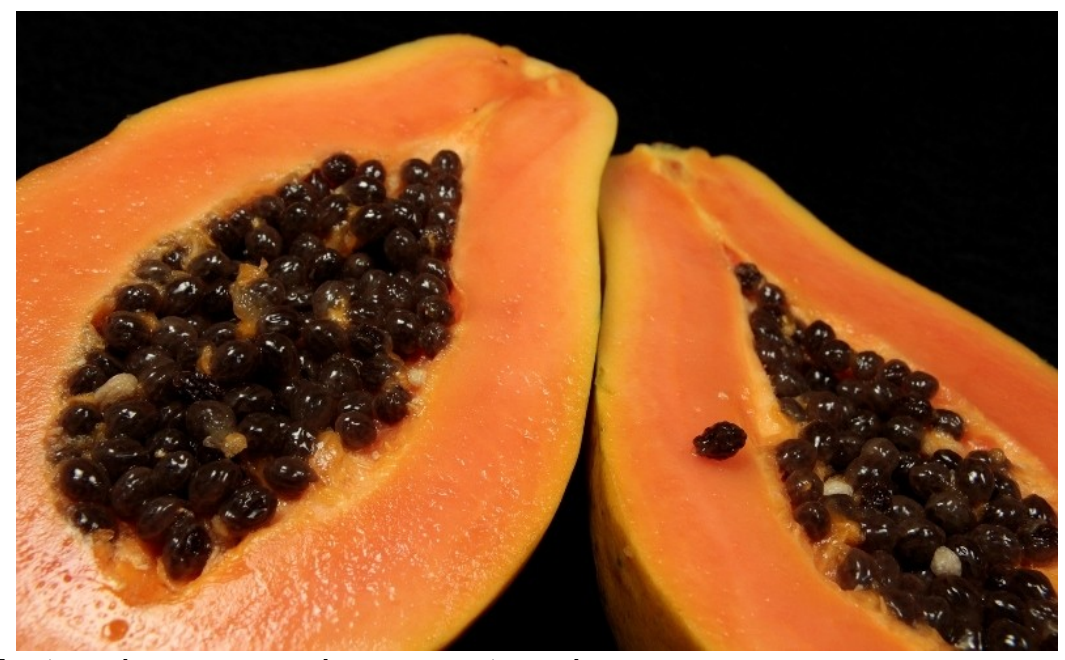

FIGURA 2 - Fruto do mamoeiro, mostrando o mesocarpo carnoso amarelovermelhado envolvendo as inúmeras sementes pretas cobertas pelo arilo. Fonte: Google (2020b)

A polpa possui características sensoriais atrativas (textura, cor e aroma), químicas (teor de sólidos solúveis, acidez e bom equilíbrio entre açúcares e ácidos orgânicos) e digestivas, que o tornam um alimento ideal e saudável para pessoas de todas as idades. Além disso, destaca-se por possuir vários nutrientes prontamente disponíveis à digestão e absorção. Conforme Silva et al. (2015), seu valor nutricional está relacionado com o teor de açúcares, pró vitamina $A$ ( $\beta$-caroteno) e vitamina $C$ (ácido ascórbico), além de ter uma boa atividade funcional associada à capacidade laxante. Segundo Roger (2006) e Silva et al. (2015), a polpa é também rica em ferro, cálcio, magnésio, potássio, fósforo, vitamina $\mathrm{K}$, tiamina, riboflavina e niacina podendo tais nutrientes variar conforme a cultivar, grau de maturação, época do ano, clima, tipo e fertilidade do solo. A composição centesimal e em micronutrientes do mamão formosa e papaia, são apresentados na Tabela 1.

TABELA 1 - Composição centesimal e de micronutrientes da parte comestível crua do mamão formosa e papaia

\begin{tabular}{lcc}
\hline Componentes $\mathbf{1 0 0} \mathbf{~ g}^{-1}$ & Formosa & Papaia \\
\hline${\text { Umidade }(\%)^{*}}_{\text {Energia }(\mathrm{kcal})^{*}}$ & 86,9 & 88,6 \\
${\text { Carboidratos }(\mathrm{g})^{*}}_{\text {Proteínas }(\mathrm{g})^{*}}^{45(190 \mathrm{~kJ})}$ & $40(168 \mathrm{~kJ})$ \\
Lipídios $(\mathrm{g})^{*}$ & 11,6 & 10,4 \\
Fibra alimentar $(\mathrm{g})^{*}$ & 0,8 & 0,5 \\
Cinzas $(\mathrm{g})^{*}$ & 0,1 & 0,1 \\
Cálcio $(\mathrm{mg})^{*}$ & 1,8 & 1,0 \\
& 0,6 & 0,4 \\
& 25 & 22
\end{tabular}


Magnésio $(\mathrm{mg})^{*}$

Fósforo $(\mathrm{mg})^{\star *}$

Ferro $(\mathrm{mg})^{* *}$

Potássio $(\mathrm{mg})^{\star *}$

Sódio $(\mathrm{mg})^{* *}$

Zinco $(\mathrm{mg})^{\star *}$

Vitamina $A(\mu \mathrm{g})^{* *}$

Vitamina $B_{1}(\mathrm{mg})^{\star \star}$

Vitamina $B_{2}(\mathrm{mg})^{* *}$

Vitamina $B_{3}(\mathrm{mg})^{* *}$

Vitamina $B_{6}(\mathrm{mg})^{\star *}$

Vitamina $B_{12}(\mu \mathrm{g})^{* *}$

Vitamina $C(\mathrm{mg})^{* *}$

Vitamina $E(\mathrm{mg})^{* *}$

Folatos $(\mu \mathrm{g})^{* *}$

NA = Não aplicável

*Fonte: Taco (2011)

${ }^{* *}$ Fonte: Roger (2006)

${ }^{* * *}$ Não foi especificada a variedade de mamão

O mamão é um fruto climatérico que apresenta significativo aumento da taxa respiratória e da produção de etileno após a colheita, completando o amadurecimento em aproximadamente uma semana sob condições ambientais, o que lhe confere a característica de ser altamente perecível (PAN et al., 2017).

\section{CULTIVARES DE MAMÃO MAIS EXPLORADAS}

No Brasil, a cultura do mamoeiro sustenta-se em estreita base genética, sendo bastante limitado o número de cultivares plantados nas principais regiões produtoras. Conforme Reis et al. (2015), os grupos 'Solo' e 'Formosa' são as cultivares mais exploradas no país. Dentre os híbridos do grupo 'Solo', destacam-se 'Sunrise Solo' e 'Improved Sunrise Solo Line cv. 72/12', conhecidos, respectivamente, como mamão papaia e mamão havaí (Figura 3). E no grupo 'Formosa' (Figura 4), sobressaem-se 'Tainung n.1' e 'Tainung n.2' (SERRANO; CATTANEO, 2010).

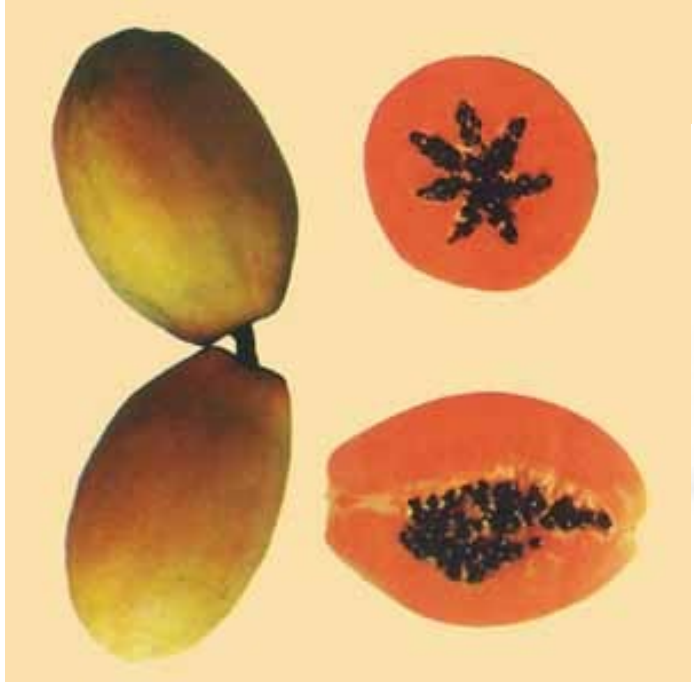

A

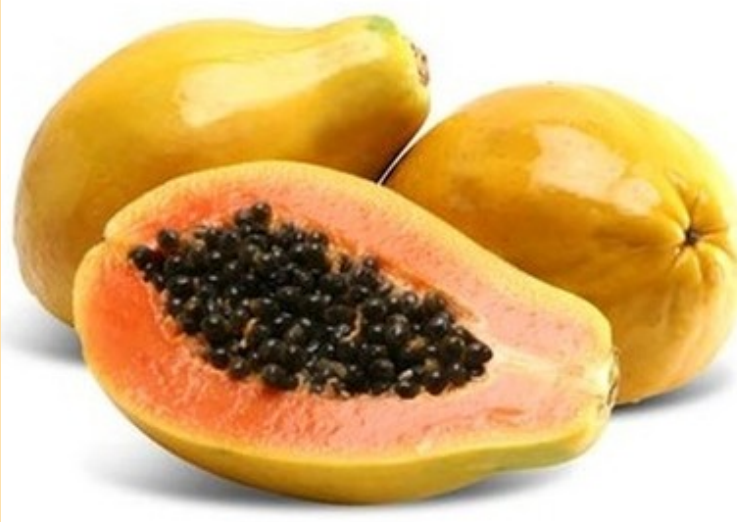

$B$

FIGURA 3 - Híbridos de mamão da cultivar 'Solo'. A = 'Sunrise Solo', B = 'Improved Sunrise Solo Line cv. 72/12'

Fonte: Google (2020c;d) 


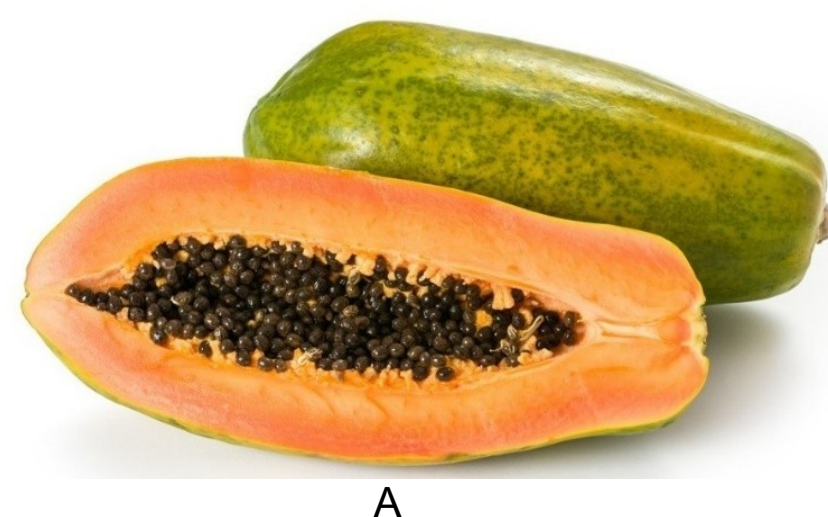

A

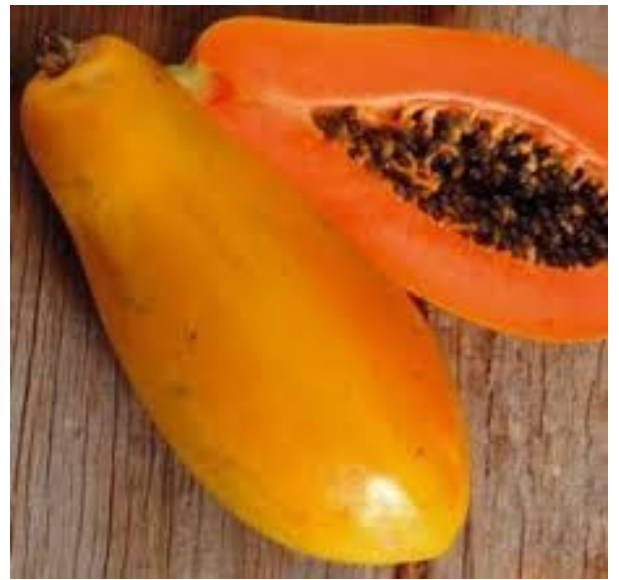

B

FIGURA 4 - Híbridos de mamão da cultivar 'Formosa'. A = 'Tainung n.1', B = 'Tainung n.2'

Fonte: Google (2020e; 2020f)

Visando exportação, as variedades do grupo 'Solo' são preteridas, pois apresentam polpa avermelhada, tamanho pequeno (300 a $650 \mathrm{~g}$ ), maior resistência ao armazenamento, precocidade e alta produtividade; enquanto que as do grupo 'Formosa', com polpa laranja-avermelhada, tamanho médio (1.000 a $1.300 \mathrm{~g}$ ), baixa resistência ao transporte e ao frio, e maturação rápida, apresentam maior demanda interna (DIAS et al., 2011).

De acordo com Serrano e Cattaneo (2010), os municípios de Pinheiros-ES, Prado-BA e Porto Seguro-BA são os maiores produtores de mamão do grupo 'Formosa' (principalmente o híbrido importado 'Tainung n.1'), e Linhares-ES e Sooretama-ES são os maiores produtores de mamão do grupo 'Solo' (principalmente 'Golden' e ‘Golden THB' para exportação e 'Sunrise Solo' para o mercado nacional).

O fruto do mamoeiro é susceptível a doenças como a mancha anelar, varíola (pinta preta), podridão peduncular e antracnose, que restringem o mercado do fruto fresco (OLIVEIRA et al., 2011). Associado a isso, Freire Júnior e Soares (2018), verificaram que as principais perdas na cadeia produtiva de mamão, em municípios da Bahia e Espírito Santo (estados com maior produção brasileira, perfazendo juntos um total de aproximadamente $70 \%$ da produção nacional) se devem a fatores bióticos, decorrentes da infecção pelos fungos Colletotrichum gloeosporioides, Phoma caricae-papayae e Fusarium spp; e fatores abióticos, causados por impactos e ferimentos ocorridos no campo e ferimentos ocorridos após a colheita, principalmente nas fases de embalagem, transporte de carga e descarga, tanto no packinghouse quanto nas centrais de abastecimento ou centrais de distribuição dos supermercados nas cidades. Daí a necessidade da adoção de estratégicas de industrialização, que visam dar maior sustentabilidade ao comércio da cultura, aproveitando ao máximo os frutos que apresentam inviabilidade de comercialização in natura.

\section{NÉCTAR: MERCADO, LEGISLAÇÃO E VANTAGENS DO PROCESSAMENTO TECNOLÓGICO}

As mudanças sócio-político-econômicas e ambientais advindas do século XVIII e XIX, consequentes da chamada Revolução Industrial, culminaram no século 
XX com a implantação e aperfeiçoamento dos conhecimentos da área de tecnologia de alimentos, permitindo a industrialização em massa, e uma melhor e mais duradoura conservação e variedade de produtos alimentícios (LEONARD; AZEVEDO, 2018). Associado a isso, o hábito do consumo de produtos processados, como o néctar, tem aumentado devido à falta de tempo da população, praticidade oferecida por esses produtos, substituição ao consumo de bebidas carbonatadas, valor nutritivo e preocupação com a ingestão de alimentos mais saudáveis (BEZERRA; ALENCAR, 2018). Para Linhares e Carmo (2018), isso tem estimulado a abertura de novas empresas que se amparam na produção de alimentos destinados a esse perfil de consumidores.

Para se ter uma ideia do crescimento do mercado brasileiro de alimentos e bebidas, pesquisa realizada em 2015 pela Euromonitor International (2016), considerou o Brasil como o quinto maior mercado global desses congêneres com movimentação de vendas estimada em aproximadamente 27,5 bilhões de dólares, tendo uma taxa média de crescimento de $20 \%$, entre 2012 e 2015, contra um aumento de apenas $8 \%$ do resto do mundo. Segundo a mesma agência, estima-se que o mercado de alimentação saudável no Brasil cresça 4,41\% até o ano de 2021 .

De acordo com estudo realizado pela Federação das Indústrias do Estado de São Paulo (FIESP) e pelo Instituto de Tecnologia de Alimentos (ITAL), tendências mostram uma maior busca dos consumidores por alimentos e produtos alimentícios considerados mais saudáveis. Dentre as principais categorias de produtos que despertam o desejo dos consumidores estão os "sucos prontos para beber", relatados em $27 \%$ das escolhas, ficando somente atrás da categoria dos "iogurtes" e "bolachas e biscoitos" (FIESP/ITAL, 2010).

Segundo Silva et al. (2015) e Toledo et al. (2018), o mercado de bebidas consideradas mais saudáveis e/ou frescas (néctares e sucos, por exemplo) vem ganhando espaço e ultrapassando a comercialização das bebidas carbonatadas (refrigerantes). Conforme citado pelos mesmos autores, uma pesquisa feita pela Associação Brasileira das Indústrias de Refrigerantes e Bebidas não Alcoólicas (ABIR) entre 2010 e 2016 evidenciou crescimento de $69,1 \%$ dos néctares contra $15 \%$ dos refrigerantes, indicando que aproximadamente um terço dos brasileiros prefere bebidas sem adoçantes, com ingredientes vegetais ou fabricadas a partir de ingredientes naturais. Conforme relatório da Abir (2018), apesar de algumas variações negativas observadas nos anos de 2015 e 2016, o consumo per capita de sucos e néctares teve um crescimento nos últimos oito anos, passando dos 3,9 L ano- em 2010, para 5,31 L ano-1 em 2017, com pico de 6,4 L ano-1 em 2014.

Apesar do considerável aumento na ingestão de néctar, os sabores ainda mais consumidos são laranja, uva, goiaba, maracujá, pêssego, manga e abacaxi. Entretanto, devido à diversidade de frutas no país e a miscigenação cultural, a procura por sabores diversificados tem levado as empresas a desenvolverem novos produtos para atender a demanda (NOGUEIRA et al., 2019).

No Brasil a regulamentação da fabricação de néctares, bem como registro, classificação, padronização e inspeção, é feita pelo Ministério da Agricultura, Pecuária e Abastecimento (MAPA). Conforme este órgão, tais bebidas são consideradas não fermentadas, não alcoólicas, constituídas por suco ou polpa, variando de 25 a $50 \%$, adicionadas de água, açúcar e opcionalmente ácidos, destinadas ao consumo direto (BRASIL, 2003; BRASIL, 2009). Segundo a mesma entidade governamental, polpa de fruta é o produto não fermentado, não concentrado, não diluído, obtido de frutos polposos, através de processo tecnológico adequado, com um teor mínimo de sólidos totais proveniente da parte comestível do 
fruto (BRASIL, 2000; BRASIL, 2009); e suco é uma bebida não fermentada, não concentrada e não diluída (ressalvados casos específicos), obtida da fruta madura e sã, ou parte vegetal de origem, por meio de processo tecnológico adequado, de cor, aroma e sabor característicos da fruta, submetido a tratamento que assegure sua conservação e apresentação até o momento do consumo (BRASIL, 2003; BRASIL, 2009).

Por definição, o néctar de mamão é uma bebida não fermentada, obtida da dissolução, em água potável, da parte comestível do mamão ( $C$. papaya L.), e açúcares, destinado ao consumo direto, podendo ser adicionado de ácidos. Para ser caracterizada como tal, a bebida deve atender aos seguintes parâmetros mínimos: $35 \%$ de suco ou polpa, $10^{\circ}$ Brix de sólidos solúveis a $20^{\circ} \mathrm{C}, 6 \%$ de açúcares totais e 0,10\% de acidez em ácido cítrico (BRASIL, 2003).

O segmento de frutas processadas entrou na era da diversificação, visando atender a nichos de mercado diferenciados. Várias são as vantagens de se processar frutas como o mamão para se produzir néctar, dentre elas: aumentar a vida útil do alimento; uniformizar a qualidade; facilitar a armazenagem e distribuição; facilitar o consumo; manter a qualidade sanitária; aumentar a disponibilidade e reduzir as perdas. Associado a isso, pode-se considerar ainda a boa aceitação do néctar de mamão, além da facilidade de elaboração e baixo custo para se produzir o produto, quando comparado a outras formas de conservação, conforme verificado por Matsuura et al. (2004) e Braga; Conti-Silva (2014; 2015).

A elaboração de geleias e doces necessitam de altas temperaturas, por longo tempo, além de pectina e alta concentração de açúcar. Para se empregar o fruto do mamão como um ingrediente em produtos lácteos, por exemplo, o custo do produto final acaba aumentando, pois os outros ingredientes entrarão no valor dos custos da produção. Tais fatores acabam por onerar a produção desses produtos em detrimento da elaboração do néctar, que necessita somente de água, menor quantidade de açúcar e emprego de calor num curto período de tempo (FELLOWS, 2019).

As maiores perdas do mamão são nos períodos pós-colheita em decorrência do manuseio e armazenagem inadequados que promovem danos mecânicos. Tais danos associados às características intrínsecas do fruto, como elevado teor de umidade, alta taxa respiratória e textura macia; e a presença de fitopatógenos na superfície exacerbam ainda mais a situação (BARROS et al., 2018). Nesse sentido, a adoção de tecnologias visando a redução das perdas pós colheita, como o processamento do fruto para obtenção do néctar, são essenciais para se manter e ofertar ao longo de todo o ano produtos de qualidade à população e por um baixo custo.

\section{CONSIDERAÇÕES FINAIS}

O mamão nacional ganha espaço nos mercados interno e de exportação, apesar de certas dificuldades enfrentadas na logística, transporte, armazenagem e manuseio, que promovem grande parte da perda do produto ao longo da cadeia de suprimentos. Nesse sentido, o desenvolvimento de alternativas de processamento, como a elaboração do néctar, é uma alternativa promissora que pode garantir a oferta e qualidade do alimento à população, mesmo que na forma transformada.

\section{REFERÊNCIAS}

ABF - Anuário Brasileiro da Fruticultura; B.B.; CARVALHO, C.; TREICHEL, M.; SANTOS, C.E. (Eds.). Santa Cruz do Sul: Editora Gazeta Santa Cruz, 2018. 49p. 
Disponível em: http://www.editoragazeta.com.br/sitewp/wp-content/uploads/2018/04/ FRUTICULTURA_2018_dupla.pdf. Acesso em: 29/06/2019.

ABIR - Associação Brasileira das Indústrias de Refrigerantes e Bebidas não Alcoólicas, 2018. Disponível em: https://abir.org.br/o-setor/dados/nectares/. Acesso em: 29/07/2019.

ABRAFRUTAS - Associação Brasileira dos Produtores e exportadores de frutas e derivados, 2018. Disponível em: http://abrafrutas.org/2018/08/14/fruticultura-setor-em-expansao/. Acesso: 29/07/2019.

ABRAFRUTAS - - Associação Brasileira dos Produtores e exportadores de frutas e derivados .2020. Disponível em: https://abrafrutas.org/2020/01/28/8825/. Acesso em: 10/02/2020.

BARROS, T.F.S.; RIOS, E.S.C.; MAIA, L.D.M.; DANTAS, R.L.; SILVA, S.M. Qualidade de frutos de cultivares de mamão comercializados em supermercados de Campina Grande - PB. Revista Agropecuária Técnica, v.39, n.2, p.129-142, 2018. Disponível em: https://doi.org/10.25066/agrotec.v39i2.38109. DOI: 10.25066/agrotec.v39i2.38109. Acesso em: 13/02/2020.

BEZERRA, I. N.; ALENCAR, E. S. Associação entre excesso de peso e tamanho das porções de bebidas consumidas no Brasil. Revista de Saúde Pública, v. 52, n. 21, p. 1-11, 2018. Disponível em: https://doi.org/10.11606/S1518-8787.2018052000082. DOI: 10.11606/S1518-8787.2018052000082. Acesso em: 10/02/2020.

BRAGA, H.F.; CONTI-SILVA, A.C. Determinação da doçura ideal em néctar de mamão adicionado de açúcar. Ciência Rural, v.44, n.4, p.723-727, 2014. Disponível em: http://dx.doi.org/10.1590/S0103-84782014000400025. DOI: 10.1590/S010390162004000600007. Acesso em: 13/02/2020.

BRAGA, H.F.; CONTI-SILVA, A.C. Papaya nectar formulated with prebiotics: Chemical characterization and sensory acceptability. Lebensmittel-Wissenschaft \& Technologie - Food Science and Technology, v.62, n.1, p.854-860, 2015. Disponível em: http://dx.doi.org/10.1016/j.Iwt.2014.12.064. DOI: 10.1016/j.Iwt.2014.12.064. Acesso em: 11/02/2020.

BRASIL. Ministério da Agricultura, Pecuária e Abastecimento. Instrução Normativa n.01, de 07 de janeiro de 2000. Regulamento técnico para a fixação dos padrões de identidade e qualidade para polpas de frutas. Diário Oficial da União, Brasília, DF, 2000.

em:

http://extranet.agricultura.gov.br/sislegis-consulta/consultarLegislacao.do? operacao=visualizar\&id=7777. Acesso em: 29/07/2019.

BRASIL. Ministério da Agricultura, Pecuária e Abastecimento. Instrução Normativa n.12, de 04 de setembro de 2003. Regulamento técnico para os padrões de identidade e qualidade dos néctares de abacaxi, acerola, cajá, caju, goiaba, graviola, mamão, manga, maracujá, pêssego e pitanga. Anexo III. Diário Oficial da União, 
Brasília, DF, 2003. Disponível em: http://extranet.agricultura.gov.br/sislegis-consulta/ consultarLegislacao.do?operacao=visualizar\&id=2831. Acesso em: 29/07/2019.

BRASIL. Ministério da Agricultura, Pecuária e Abastecimento. Decreto $\mathbf{n}^{\circ} \mathbf{6 . 8 7 1}$, de 04 de junho de 2009. Regulamenta a Lei $n^{\circ}$ 8.918, de 14 de julho de 1994, que dispõe sobre a padronização, a classificação, o registro, a inspeção, a produção e a fiscalização de bebidas. Diário Oficial da União, Brasília, DF, 2009. Disponível em: http://extranet.agricultura.gov.br/sislegis-consulta/consultarLegislacao.do? operacao=visualizar\&id=20271. Acesso em: 29/07/2019.

CAMPOSTRINI, E.; GLENN, D.M. Ecophysiology of papaya: a review. Brazilian Journal of Plant Physiology, v.19, n.4, p.413-424, 2007. Disponível em: http://dx.doi.org/10.1590/S1677-04202007000400010. DOI: 10.1590/S167704202007000400010. Acesso em: 12/12/2019.

COLTRE, J.; MARTINS, L.M. A industrial 4.0 na gestão estratégica: desafios e oportunidades para as empresas brasileiras. Revista Terra \& Cultura: Cadernos de Ensino e Pesquisa, v.34, n.esp., p.110-128, 2018. Disponível em: http://periodicos.unifil.br/index.php/Revistateste/article/view/1012. Acesso em: 03/03/2020.

COTRUT, R.; BUTCARU, A.; MIHAI, C.; STÃNICÃ, F. Carica papaya L. cultivated in greenhouse conditions. Journal of Horticulture, Forestry, and Biotechnology, v.3, p.130-136, 2017. Disponível em: https://www.usab-tm.ro/Journal-HFB/2017/Lucrari\%20PDF\%2021(3)/22Cotrut \%20Ramona\%20BUN.pdf. Acesso em: 01/02/2020.

DE MARCHI, E.; CAPUTO, V.; NAYGA JR., R.M.; BANTERLE, A. Time preferences and food choices: evidence from a choice experiment. Food Policy, v.62, p.99-109, 2016. Disponível em: https://doi.org/10.1016/j.foodpol.2016.05.004. DOI: 10.1016/j.foodpol.2016.05.004. Acesso em: 12/01/2020.

DIAS, N.L.P.; OLIVEIRA, E.J.; DANTAS, J.L.L. Avaliação de genótipos de mamoeiro com uso de descritores agronômicos e estimação de parâmetros genéticos. Pesquisa Agropecuária Brasileira, v.46, n.11, p.1471-179, 2011. Disponível em: http://dx.doi.org/10.1590/S0100-204X2011001100008. DOI: 10.1590/S0100204X2011001100008. Acesso em: 10/10/2019.

DINIZ, G.L.; SALES, G.N.; SOUSA, V.F.O.; ANDRADE, F.H.A.; SILVA, S.S. et al. Produção de mudas de mamoeiro sob salinidade da água de irrigação e adubação fosfatada. Revista de Ciências Agrárias, v.41, n.1, 2018. Disponível em: https://revistas.rcaap.pt/index.php/rca/article/view/16643. DOI: 10.19084/RCA17067. Acesso em: 29/01/2020.

EMBRAPA - Empresa Brasileira de Pesquisa Agropecuária. 2017. Mandioca e Fruticultura: produção brasileira de mamão 2017. Disponível em: http://www.cnpmf.embrapa.br/Base_de_Dados/index_pdf/dados/brasil/mamao/ b1_mamao. Acesso em: 10/02/2020.

EUROMONITOR INTERNATIONAL. Soft drinks global overview: growth opportunities between category lines. 2016. Disponível em: 
https://www.euromonitor.com/soft-drinks-global-overviewgrowth-opportunitiesbetween-category-lines/report. Acesso em: 10/01/2019.

FELLOWS, P.S. Tecnologia do processamento de alimentos: princípios e práticas. 4.ed. Porto Alegre: Artmed. 944p.

FIESP/ITAL - Federação das Indústrias do Estado de São Paulo; Instituto de Tecnologia de Alimentos. Brasil Foods Trends 2020. 2010. Disponível em: http://www.alimentosprocessados.com.br/arquivos/Consumo-tendencias-einovacoes/Brasil-Food-Trends-2020.pdf. Acesso em: 10/10/2020.

FAOSTAT - Food and Agriculture Organization of United Nations. Productio. Crops Primary. 2016. Disponível em: http://faostat.fao.org/. Acesso em: 10/03/2017.

FAOSTAT - Food and Agriculture Organization of United Nations. 2018. Disponível em: http://www.fao.org/faostat/es/\#data/QC. Acesso em: 29/07/2019.

FREIRE JÚNIOR, M.; SOARES, A.G. Diagnóstico e procedimentos para a redução de perdas na cadeia produtiva do mamão. v.1. Embrapa Agroindústria de Alimentos: Circular Técnica (INFOTECA-E), 2018. 18p. Disponível em: https://www.infoteca.cnptia.embrapa.br/infoteca/bitstream/doc/1105257/1/

CircularTecnica1.pdf. Acesso em: 12/02/2020.

GOOGLE.

2020a.

Disponível

em:

https://lh3.googleusercontent.com/proxy/cNOuAAQNHAoxNVffbV58EsnsKaYRnKYFK3cePK5NgdDqtg7J4r5kX_VqoGtuctCA4Sc2uRd84njiFiTrXITcYPQNytYibQ2Gi0Pk S2c4rxeja-NeN8s_MU92IYGEVCIS6Zil4wkeHOQHYAzXhPfe-

SVfh5WZEyl8vnq718Q1gtKexDU1hz0cuJ3oLg. Acesso em: 12/02/2020.

GOOGLE.

2020b.

Disponível

em:

https://www.agron.com.br/imagens/publicacoes/2014/07/17/topico_40155_wwwagron-com-br_3596_mamao.jpg. Acesso em: 12/02/2020.

GOOGLE.

2020c.

Disponível

em:

https://www.biosementes.com.br/loja/product_images/e/641/mamao-

sunrisesolo_68509_std.jpg. Acesso em: 07/01/2020.

GOOGLE. 2020d. Disponível em: https://www.redeultramercado.com.br/redeultramercado/fotos/g334388.jpg. Acesso em: 07/01/2020.

GOOGLE. 2020e. Disponível em: https://http2.mlstatic.com/sementes-de-mamoformosa-hibrido-tainung-f1-10-gramas-D_NQ_NP_755233-

MLB31525734445_072019-F.jpg. Acesso em: 07/01/2020.

GOOGLE. 2020f. Disponível em: https://encrypted-tbn0.gstatic.com/images?q=tbn \%3AANd9GcRx15lwJXMCQHquFAE4X8JYeRsJ4-Gqld7tLsyMJQET3Gj-YamR.

Acesso em: 07/01/2020. 
IBGE - Instituto Brasileiro de Geografia e Estatística. 2010. Disponível em: http://www.ibge.gov.br/. Acesso em: 20/12/2012.

JACOBSEN, R.H.F.; SILVA, E.A.; SILVEIRA, I.P.; ROLIM, E.L.G.; SILVA, L.K. et al. Cadeia produtiva da produção de suco natural na agricultura familiar: estudo de caso suco tropical. Revista Brasileira de Ciências da Amazônia, v. 7, n. 2, p. 1-47, 2018.

Disponível

em: http://www.periodicos.unir.br/index.php/rolimdemoura/article/view/2219. Acesso em: 29/01/2020.

LEONARD, J.G.; AZEVEDO, B.M. Métodos de conservação de alimentos. Revista Saúde em Foco, ed.10, p.51-61, 2018. Disponível em: http://portal.unisepe.com.br/unifia/wp-content/uploads/sites/10001/2018/06/006_M \%C3\%89TODOS_DE_CONSERVA\%C3\%87\%C3\%830_DE_ALIMENTOS.pdf. Acesso em: $13 / 02 / 2020$.

LINHARES, F.R.; CARMO, F.L. Uma abordagem do cenário geral de sucos industrializados no contexto da alimentação saudável por meio de patentes. Cadernos de Prospecção, v.11, n.5, Ed. Esp. VIII ProspeCT\&I, p.1698-1711, 2018. Disponivel em: http://dx.doi.org/10.9771/cp.v12i5.27325. DOI: 10.9771/cp.v12i5.27325. Acesso em: 12/02/2020.

MARIN, S.L.D. Mamão papaya: produção, pós-colheita e mercado. Fortaleza: Instituto Frutal, 2004. 82p.

MATSUURA, F.C.A.U.; FOLEGATTI, M.I.S.; CARDOSO, R.L.; FERREIRA, D.C. Sensory acceptance of mixed nectar of papaya, passion fruit and acerola. Scientia Agricola, v.61, n.6, p.604-608, 2004. Disponível em: http://dx.doi.org/10.1590/S0103-90162004000600007. DOI: 10.1590/S010390162004000600007. Acesso em: 13/02/2020.

MING, R.; HOU, S.; FENG, H.; YU, Q.; DIONNE-LAPORTE, A. et al. The draft genome of the transgenic tropical fruit tree papaya (Carica papaya Linnaeus). Nature, v.452, n.7190, p. 991-996, 2008. Disponível em: http://dx.doi.org/10.1038/nature06856. DOI: 10.1038/nature06856. Acesso em: 15/01/2020.

NOGUEIRA, A.; ZARDO, D.M.; KVITSCHAL, M.V.; COUTO, M.; ZIELINSKI, A.A.F. et al. Diversificação de negócios na propriedade frutícola: processamento de maça. Brazilian Journal of Development, v.5, n.10, p.18734-18742, 2019. Disponível em: https://doi.org/10.34117/bjdv5n10-118. DOI: $10.34117 / b j d v 5 n 10-118$. Acesso em: 03/03/2020.

OLIVEIRA, A.A.R.; SANTOS FILHO, H.P.; ANDRADE, E.C.; MEISSNER FILHO, P.E. Impacto potencial das mudanças climáticas sobre as doenças do mamoeiro no Brasil. In: GHINI, R.; HAMADA, E.; BETTIOL, W. (Ed). Impactos das mudanças climáticas sobre doenças de importantes culturas no Brasil. Jaguariúna: Embrapa Meio Ambiente, 2011. p.356. Disponível em: https://ainfo.cnptia.embrapa.br/digital/bitstream/item/58423/1/ImpactoMudancasClim aticas-Cap14.pdf. Acesso em: 12/02/2020. 
PAN, Y-G; YUAN, M-Q; ZHANG, W-M; ZHANG, Z-K. Effect of low temperatures on chilling injury in relation to energy status in papaya fruit during storage. Postharvest Biology and Technology, v.125, p.181-187, 2017. Disponível em: https://doi.org/10.1016/j.postharvbio.2016.11.016.

10.1016/j.postharvbio.2016.11.016. Acesso em: 15/01/2020.

REIS, R.C.; VIANA, E.S.; JESUS, J.L.; DANTAS, J.L.L.; LUCENA, R.S. Caracterização físico-química de frutos de novos híbridos e linhagens de mamoeiro. Pesquisa Agropecuária Brasileira, v.50, n.3, p.210-217, 2015. Disponível em: http://dx.doi.org/10.1590/S0100-204X2015000300004. DOI: 10.1590/S0100204X2015000300004. Acesso em: 03/02/2020.

RITSCHEL, P.; MAIA, J.D.G.; PROTAS, J.F.S.; GUERRA, C.C.; PEREIRA, G.E. et al. A viticultura e a agroindústria de suco de uvas americanas em um mercado em crescimento. Territoires du vin [En ligne], 9, 2018. Disponível em: https://preo.ubourgogne.fr/territoiresduvin/index.php?id=1678\&lang=fr\#quotation. Acesso em: 10/02/2020.

ROGER, J.D.P. O poder medicinal dos alimentos. Tradução: MATOS, D.A. Tatuí: Casa Publicadora Brasileira, 2006. 272p.

SALOMÃO, L.C.C.; SIQUEIRA, D.L; SANTOS, D.; BORBA, A.N. Cultivo do mamoeiro. Viçosa: Editora UFV, 2007. 73p.

SERRANO, L.A.L.; CATTANEO, L.F. O cultivo do mamoeiro no Brasil. Revista Brasileira de Fruticultura, v.32, n.3, on-line, p.0-0, 2010. Disponível em: http://dx.doi.org/10.1590/S0100-29452010000300001. DOI: 10.1590/S010029452010000300001. Acesso em: 09/02/2020.

SIM - Serviço Brasileiro de Apoio às micro e Pequenas Empresas (SEBRAE). Sistema de inteligência de Mercados. Relatório - Cenários Prospectivos da Fruticultura Brasileira em 2018. 2016. Disponível em: http://www.bibliotecas.sebrae.com.br/chronus/ARQUIVOS_CHRONUS/bds/bds.nsf/ e93e6e44c0b1ec9bed5f9ed186ab6b7e/\$File/6083.pdf. Acesso em: 03/02/2020.

SILVA JÚNIOR, E.G.; SILVA, A.F.; LIMA, J.S.; SILVA, M.F.C.; MAIA, J.M. Vegetative development and content of calcium, potassium, and sodium in watermelon under salinity stress on organic substrates. Revista Agropecuária Brasileira, v.52, n.12, 2017. Disponível em: http://seer.sct.embrapa.br/index.php/pab/article/view/24936. DOI: 10.1590/S0100-204X2017001200003. Acesso: 13/12/2019.

SILVA, E.P.; BECKER, F.S.; SILVA, F.A.; SOARES JÚNIOR, M.S.; CALIARI, M. et al. Bebidas mistas de extratos de arroz com maracujá e mamão. Revista do Instituto Adolfo Lutz, v.74, n.1, p.49-56, 2015. Disponível em: http://200.137.217.156/bitstream/ri/14306/5/Artigo\%20-\%20Edson\%20Pablo\%20da \%20Silva\%20-\%202015.pdf. Acesso em: 08/02/2020.

SILVA, P.A.; SILVA, J.A.C.; COELHO, P.O.; SILVA, J.M.; ASSUNÇÃO, E.L.S. Avaliação da qualidade de mamões (Carica papaya L.). Revista da Universidade 
$\begin{array}{llllll}\text { Vale do Rio } & \text { Verde, } & \text { v.13, } & \text { n.2, } & \text { p.465-474, }\end{array}$ http://dx.doi.org/10.5892/ruvrd.v13i1.2338. DOI: 10.5892/ruvrd.v13i1.2338. Acesso em: 01/02/2020.

TACO - Tabela Brasileira de composição de Alimentos. 4.ed. revista ampl. Núcleo de Estudos e Pesquisas em Alimentação. Campinas: NEPA-UNICAMP, 2011. Disponível em: http://www.nepa.unicamp.br/taco/tabela.php?ativo=tabela. Acesso em: 16/01/2019.

TOLEDO, M.; MOBLICCI, N.; OLIVEIRA, L. 2018. Panorama do mercado brasileiro de bebidas não-alcóolicas. Disponível em: https://www.sintec.com/pt-br/ p_innovador/panorama-do-mercado-brasileiro-de-bebidas-nao-alcoolicas/. Acesso em: 07/02/2020.

VIGITEL BRASIL. Vigilância de Fatores de Risco e Proteção para Doenças Crônicas por Inquérito Telefônico: estimativas sobre frequência e distribuição sociodemográfica de fatores de risco e proteção para doenças crônicas nas capitais dos 26 estados brasileiros e no Distrito Federal em 2017. Ministério da Saúde, Secretaria de Vigilância em Saúde, Departamento de Vigilância de Doenças e Agravos não Transmissíveis e Promoção da Saúde. Brasília: Ministério da Saúde, $2018 . \quad$ Disponível em: https://bvsms.saude.gov.br/bvs/publicacoes/vigitel_brasil_2017_vigilancia_fatores_ri scos.pdf. Acesso em: 03/02/2020. 